\title{
Attraction of Chagas disease vectors (Triatominae) to artificial light sources in the canopy of primary Amazon rainforest
}

\author{
Marcelo CM Castro1, Toby V Barrett', Walter S Santos², Fernando Abad-Franch², José A Rafael¹/+ \\ ${ }^{1}$ Instituto Nacional de Pesquisas da Amazônia, Av. André Araújo 2936, 69011-970 Manaus, AM, Brasil \\ ${ }^{2}$ Instituto Leônidas e Maria Deane-Fiocruz, Manaus, AM, Brasil
}

\begin{abstract}
Adult triatomines occasionally fly into artificially lit premises in Amazonia. This can result in Trypanosoma cruzi transmission to humans either by direct contact or via foodstuff contamination, but the frequency of such behaviour has not been quantified. To address this issue, a light-trap was set $45 \mathrm{~m}$ above ground in primary rainforest near Manaus, state of Amazonas, Brazil and operated monthly for three consecutive nights over the course of one year (432 trap-hours). The most commonly caught reduviids were triatomines, including 38 Panstrongylus geniculatus, nine Panstrongylus lignarius, three Panstrongylus rufotuberculatus, five Rhodnius robustus, two Rhodnius pictipes, one Rhodnius amazonicus and 17 Eratyrus mucronatus. Males were collected more frequently than females. The only month without any catches was May. Attraction of most of the known local T. cruzi vectors to artificial light sources is common and year-round in the Amazon rainforest, implying that they may often invade premises built near forest edges and thus become involved in disease transmission. Consequently, effective Chagas disease prevention in Amazonia will require integrating entomological surveillance with the currently used epidemiological surveillance.
\end{abstract}

Key words: Triatominae - light-trapping - Amazon rainforest - Chagas disease

Chagas disease is thought to be hypoendemic across Amazon rainforest ecoregions (Aguilar et al. 2007); transmission of the disease agent, Trypanosoma cruzi, is mediated by sylvatic triatomine bugs that occasionally invade houses or other premises and either come into direct contact with humans or contaminate their foodstuffs (Coura et al. 2002, Aguilar et al. 2007, Nóbrega et al. 2009, Valente et al. 2009). Such invasive behaviour is believed to be fairly common in Amazonia and has been linked to the attraction of adult (i.e., winged) triatomines to artificial light sources (Miles et al. 2003, Valente et al. 2009). However, this beliefs are largely based on anecdotal observations, and have to be interpreted with caution. The true epidemiological importance of triatomine attraction to artificial light sources in Amazonia remains unclear; in fact, even the frequency of such events is yet to be suitably quantified. To address this basic issue, we performed systematic nocturnal light-trapping in an uninhabited forest environment over the course of one year. The results of this unprecedented trapping effort show that several known T. cruzi vector species are commonly attracted to artificial light sources in central Amazonia. This suggests that adventitious triatomines may often reach artificially lit households near forest edges and may thereby become involved in Chagas disease transmission in the region.

Financial support: CNPq (472978/2003-9), INPA, FIOCRUZ-FAPEAM

+ Corresponding author: jarafael@inpa.gov.br

Received 27 July 2010

Accepted 20 September 2010
Triatomine collections were made at the Tropical Silviculture Station of the Brazilian National Institute of Amazonian Research (INPA) (2 $\left.35^{\prime} \mathrm{S} 60^{\circ} 06^{\prime} \mathrm{W}\right)$, a region mainly composed of primary terra firme rainforest. Within the context of a broader study on forest canopy insect diversity, a light-trap, consisting of a vertical white sheet simultaneously lit by a 250 -watt mercury vapour lamp, a 20 -watt black light and a 20 watt black light bulb, was set $45 \mathrm{~m}$ above ground on a tower platform. The trap was operated monthly from January-December 2004 for three consecutive nights from 6:00 pm-6:00 am during the waning moon-new moon transition, resulting in a total of 432 trap-hours. Specimens landing on the sheet were collected, placed in standard killing jars and brought to the laboratory for species determination (Lent \& Wygodzinsky 1979). All specimens, including triatomines and other Reduviidae, were deposited at the INPA Invertebrate Collection in Manaus, state of Amazonas, Brazil.

A total of 230 Reduviidae specimens belonging to eight subfamilies were collected (MCM Castro \& JA Rafael, unpublished observations). The most abundant subfamily was Triatominae, accounting for $32.6 \%$ of the total catch with 75 specimens representing seven species and three genera (Table). Triatomine catches were fairly well distributed throughout the sampling period, with a trend towards higher trapping productivity over the second half of the year and an apparent peak in October (Figure). The only month without any catches was May. Overall, male triatomine bugs were 3.4 times as likely as females to be caught in the canopy-level light-trap.

Panstrongylus geniculatus was the most commonly caught species: it was represented by 1-9 individuals in all monthly catches except for May (Table); the sex 
TABLE

Monthly triatomine catches using a canopy-level light-trap in primary Amazon rainforest at the Tropical Silviculture Station, Brazilian National Institute of Amazonian Research, state of Amazonas, Brazil, 2004

\begin{tabular}{|c|c|c|c|c|c|c|c|c|c|c|c|c|c|c|c|}
\hline \multirow[b]{2}{*}{ Species } & \multicolumn{12}{|c|}{ Months } & \multirow[b]{2}{*}{ Male } & \multirow[b]{2}{*}{ Female } & \multirow[b]{2}{*}{ Total } \\
\hline & Jan & $\mathrm{Feb}$ & Mar & Apr & May & Jun & Jul & Aug & Sep & Oct & Nov & Dec & & & \\
\hline Panstrongylus geniculatus & 1 & 4 & 2 & 3 & - & 2 & 2 & 3 & 3 & 9 & 4 & 5 & 28 & 10 & 38 \\
\hline Panstrongylus lignarius & - & - & 1 & - & - & - & - & 3 & - & 3 & 1 & 1 & 6 & 3 & 9 \\
\hline Panstrongylus rufotuberculatus & - & - & - & - & - & 1 & - & - & - & 2 & - & - & 3 & - & 3 \\
\hline Rhodnius robustus & - & - & 1 & - & - & - & 1 & - & - & 3 & - & - & 3 & 2 & 5 \\
\hline Rhodnius pictipes & - & - & - & - & - & - & - & 1 & 1 & - & - & - & 1 & 1 & 2 \\
\hline Rhodnius amazonicus & - & - & - & - & - & 1 & - & - & - & - & - & - & 1 & - & 1 \\
\hline Eratyrus mucronatus & 2 & 1 & 2 & 2 & - & - & 1 & 3 & - & 5 & 1 & - & 16 & 1 & 17 \\
\hline Total & 3 & 5 & 6 & 5 & - & 4 & 4 & 10 & 4 & 22 & 6 & 6 & 58 & 17 & 75 \\
\hline
\end{tabular}

ratio $(\delta:$ ) for this species, and generally for the genus Panstrongylus, was close to 3:1. Most $P$. geniculatus and Panstrongylus lignarius, as well as all three Panstrongylus rufotuberculatus specimens, were collected in the second half of the year. Eratyrus mucronatus, a relatively little-studied species, was consistently caught across

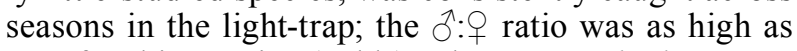
16:1 for this species (Table). The genus Rhodnius was represented by three species. Two of them, Rhodnius robustus and Rhodnius pictipes, are common in Amazonia and have been implicated in Chagas disease transmission (Abad-Franch \& Monteiro 2007, Valente et al. 2009), whereas Rhodnius amazonicus is a rare species hitherto known only from type specimens and a few additional collections in French Guiana (Bérenger \& Pluot-Sigwalt 2002, Bérenger et al. 2009).

Twenty-seven triatomine species in nine genera and five tribes have been recorded to date in Amazonia. Except for spatially discrete foci of true domestic (i.e., householdbreeding) populations, Amazonian triatomines are essentially sylvatic (Abad-Franch \& Monteiro 2007, Aguilar et al. 2007). They exploit a variety of forest ecotopes, including palm tree crowns, hollow trees and vertebrate nests and burrows (Lent \& Wygodzinsky 1979, Barrett 1991). Flying from such ecotopes, adult specimens may enter a house or fall into a food-processing device; this is currently regarded as the main mechanism underlying Chagas disease epidemiology in Amazonia (Coura et al. 2002, Aguilar et al. 2007, Valente et al. 2009). For instance, large peridomestic palm trees are often infested and can act as a major source of adventitious Rhodnius specimens in several Latin American biomes, including Amazonia (Romaña et al. 1999, Fitzpatrick et al. 2008, Gurgel-Gonçalves et al. 2008, Abad-Franch et al. 2010, Calzada et al. 2010).

Attraction of adult triatomine bugs to artificial light sources can enhance the risk of Chagas disease transmission under such circumstances (Coura et al. 2002,

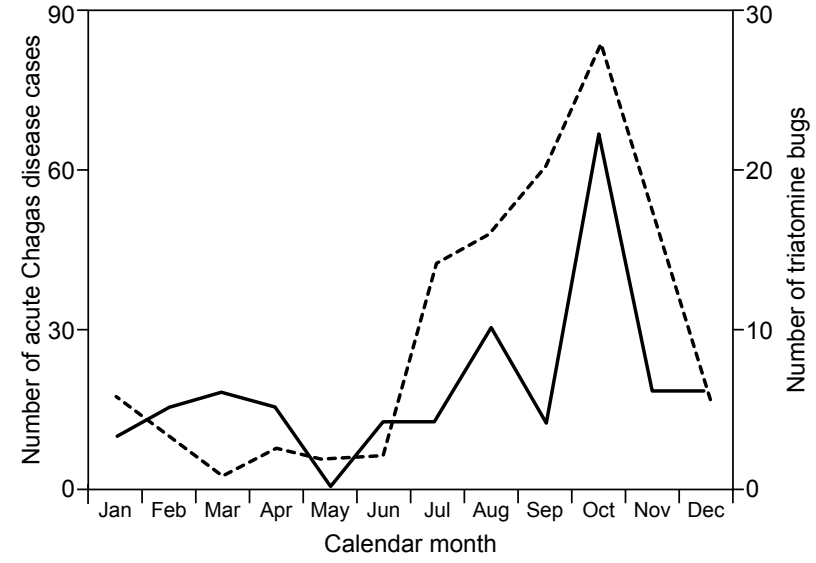

Broken line: monthly numbers of acute Chagas disease cases notified from the Brazilian Amazon Region, 2007-2009 (www.datasus. gov.br); solid line: triatomine catches in a canopy-level light-trap in primary Amazon rainforest, 2004.

Miles et al. 2003). Both field (Noireau \& Dujardin 2001, Zeledón et al. 2001, Carbajal de la Fuente et al. 2007) and laboratory studies (e.g., Minoli \& Lazzari 2006) suggest that triatomine bugs make use of artificial light cues while actively dispersing; our results lend further support to this view by showing that forest triatomines can be routinely collected in light-traps in primary rainforest environments. Electric light, a trait that is typical of human residences, may therefore play a key role also in household invasion by adult sylvatic triatomines. Other potential attractors that might be used by dispersing triatomines as guiding cues, such as radiant heat or human odors (Minoli \& Lazzari 2006), are typical of households too. 
Our catches represent a large fraction of the triatomine species known to occur in central Amazonia. The study site lies within the Uatumã-Trombetas ecoregion, where 11 species (including 2 cryptic $R$. robustus forms) have been recorded. Microtriatoma trinidadensis and $R$. brethesi may also be present, but have not been collected to date (Abad-Franch \& Monteiro 2007). Our catches therefore included $\sim 70 \%$ of the locally recorded species; only Cavernicola pilosa, Cavernicola lenti and Rhodnius paraensis were not collected. This indicates that light-trapping can be used to sample most, if not all, of the epidemiologically relevant species present in Amazonian forests landscapes.

When compared with the results of surveys conducted in anthropic landscapes, our data suggest that the rich triatomine fauna of primary forests becomes heavily simplified following disturbance. For example, Naiff et al. (1998) reported only three species (P. geniculatus, $R$. robustus and $R$. pictipes) in an urban environment, and Valente et al. (2009) collected only two species (R. pictipes and P. geniculatus) in and around a rural settlement. Bérenger et al. (2009) reported similar results from French Guiana: 11 triatomine species were collected in forested areas, but only five (P. geniculatus, $P$. lignarius, $R$. pictipes, $R$. robustus, and E. mucrona$t u s$ ) were found in anthropic landscapes.

Why males of several triatomine species appear to fly more often than females to light-traps and houses remains difficult to explain. In fact, some laboratory and field studies suggest that female bugs are equally or more likely than males to start dispersive flights (Schofield et al. 1992, Gurevitz et al. 2006, Minoli \& Lazzari 2006), but males are usually caught more often at lighttraps (Noireau \& Dujardin 2001, Zeledón et al. 2001, Vázquez-Prokopec et al. 2006). This is clearly of more importance for species capable of colonising human households, which has not been reported in our study area. However, P. geniculatus can colonise peridomestic pigsties in Amazonia (Valente et al. 1998), and Eratyrus mucronatus, $P$. geniculatus, $P$. rufotuberculatus and the $P$. lignarius population from the Marañón Valley, Peru (formerly known as $P$. herreri) have all been reported to breed within houses in other biomes (Barrett 1991, Noireau et al. 1995, Wolff \& Castillo 2000, AbadFranch et al. 2001, Cuba Cuba et al. 2002).

Triatomine trapping appeared to be more productive towards the end of the year, which coincides with the local dry season. Approximately $75 \%$ of catches occurred between July-December, when the monthly rainfall averaged $\sim 95 \mathrm{~mm}$. In contrast, the monthly rainfall from January-May averaged $\sim 280 \mathrm{~mm}$ (www.inmet.gov.br). This trend, noted also by Naiff et al. (1998) for P. geniculatus specimens flying into houses in Manaus, needs obviously to be confirmed with more data. It is nonetheless worth highlighting that reports of acute Chagas disease cases are also strongly biased towards the second half of the year in the Brazilian Amazon (Figure). This observation is merely correlational, but hints at a potential link between increased vector flight activity and higher disease incidence in drier (and hotter) months; we believe that this possibility should be more thoroughly investigated.
The frequent and widespread attraction of Amazonian triatomines to artificial light sources poses a potentially serious health threat that is only beginning to be understood. Individual sylvatic triatomines are often infected by the time they reach the adult stage, and can transmit $T$. cruzi to humans either by direct contact or by contaminating food or food-processing equipment. The parasite is carried by triatomine bugs in both cases, and transmission must therefore be regarded as vectorborne. This raises concerns about current disease surveillance strategies, which in Amazonia strongly emphasise the detection, confirmation, and compulsory reporting of acute disease cases (SVS 2005, Aguilar et al. 2007). By overlooking the entomological aspects of surveillance, such schemes might be missing most transmission risk situations in the Amazon and, as a consequence, may drive public attention and resources away from primary disease prevention.

\section{ACKNOWLEDGEMENTS}

To N Higuchi and J dos Santos, for permitting the use of the INPA Station premises and equipment for this study, and to A da Silva Filho (in memoriam), AU Rodrigues, C Motta, F Godoi, F Baccaro, FF Xavier Filho, JM Ribeiro, J Câmara and $\mathrm{S}$ Trovisco, for their help in fieldwork.

\section{REFERENCES}

Abad-Franch F, Ferraz G, Campos C, Palomeque FS, Grijalva MJ, Aguilar HM, Miles MA 2010. Modeling disease vector occurrence when detection is imperfect: infestation of Amazonian palm trees by triatomine bugs at three spatial scales. PLoS Negl Trop Dis 4: e620.

Abad-Franch F, Monteiro FA 2007. Biogeography and evolution of Amazonian triatomines (Heteroptera: Reduviidae): implications for Chagas disease surveillance in humid forest ecoregions. Mem Inst Oswaldo Cruz 102 (Suppl. 1): 57-69.

Abad-Franch F, Paucar CA, Carpio CC, Cuba Cuba CA, Aguilar VHM, Miles MA 2001. Biogeography of Triatominae (Hemiptera: Reduviidae) in Ecuador: implications for the design of control strategies. Mem Inst Oswaldo Cruz 96: 611-620.

Aguilar HM, Abad-Franch F, Dias JCP, Junqueira ACV, Coura JR 2007. Chagas disease in the Amazon region. Mem Inst Oswaldo Cruz 102 (Suppl. 1): 47-55.

Barrett TV 1991. Advances in triatomine bug ecology in relation to Chagas disease. In KH Harris (org.), Advances in disease vector research, Vol. 8, Springer-Verlag, New York, p. 143-176.

Bérenger J-M, Pluot-Sigwalt D 2002. Rhodnius amazonicus Almeida, Santos \& Sposina, 1973, bona species, close to $R$. pictipes Stål, 1872 (Heteroptera, Reduviidae, Triatominae). Mem Inst Oswaldo Cruz 97: 73-77.

Bérenger J-M, Pluot-Sigwalt D, Pagès F, Blanchet D, Aznar C 2009. The Triatominae species of French Guiana (Heteroptera: Reduviidae). Mem Inst Oswaldo Cruz 104: 1111-1116.

Calzada JE, Pineda V, Garisto JD, Samudio F, Santamaría AM, Saldaña A 2010. Human trypanosomiasis in the eastern region of the Panama Province: new endemic areas for Chagas disease. $\mathrm{Am}$ J Trop Med Hyg 82: 580-582.

Carbajal de la Fuente AL, Minoli SA, Lopes CM, Noireau F, Lazzari CR, Lorenzo MG 2007. Flight dispersal of the Chagas disease vectors Triatoma brasiliensis and Triatoma pseudomaculata in Northeastern Brazil. Acta Trop 101: 115-119. 
Coura JR, Junqueira ACV, Fernandes O, Valente SAS, Miles MA 2002. Emerging Chagas disease in Amazonian Brazil. Trends Parasitol 18: 171-176.

Cuba Cuba CA, Abad-Franch F, Roldán RJ, Vargas VF, Pollack VL, Miles MA 2002. The triatomines of northern Peru, with emphasis on the ecology and infection by trypanosomes of Rhodnius ecuadoriensis (Triatominae). Mem Inst Oswaldo Cruz 97: 175-183.

Fitzpatrick S, Feliciangeli MD, Sánchez-Martín M, Monteiro FA, Miles MA 2008. Molecular genetics reveal that silvatic Rhodnius prolixus do colonise rural houses. PLoS Negl Trop Dis 2: e210.

Gurevitz JM, Ceballos LA, Kitron U, Gürtler RE 2006. Flight initiation of Triatoma infestans (Hemiptera: Reduviidae) under natural climatic conditions. J Med Entomol 43: 143-150.

Gurgel-Gonçalves R, Abad-Franch F, Ferreira JBC, Santana DB, Cuba Cuba CA 2008. Is Rhodnius prolixus (Triatominae) invading houses in Central Brazil? Acta Trop 107: 90-98.

Lent H, Wygodzinsky P 1979. Revision of the Triatominae (Hemiptera, Reduviidae), and their significance as vectors of Chagas' disease. Bull Am Mus Nat Hist 163: 125-520.

Miles MA, Feliciangeli MD, de Arias AR 2003. Science, medicine, and the future. American trypanosomiasis (Chagas' disease) and the role of molecular epidemiology in guiding control strategies. BMJ 326: 1444-1448.

Minoli SA, Lazzari CR 2006. Take-off activity and orientation of triatomines (Heteroptera: Reduviidae) in relation to the presence of artificial lights. Acta Trop 97: 324-330.

Naiff MF, Naiff RD, Barrett TV 1998. Vetores selváticos de doença de Chagas na área urbana de Manaus (AM): atividade de vôo nas estações secas e chuvosas. Rev Soc Bras Med Trop 31: 103-105.

Nóbrega AA, Garcia MH, Tatto E, Obara MT, Costa E, Sobel J, Araujo WN 2009. Oral transmission of Chagas disease by consumption of açaí palm fruit, Brazil. Emerg Infect Dis 15: 653-655.

Noireau F, Bosseno M-F, Carrasco R, Telleria J, Vargas F, Camacho C, Yaksic N, Brenière SF 1995. Sylvatic triatomines (Hemiptera: Reduviidae) in Bolivia: trends toward domesticity and possible infection with Trypanosoma cruzi (Kinetoplastida: Trypanosomatidae). J Med Entomol 32: 594-598.

Noireau F, Dujardin J-P 2001. Flight and nutritional status of sylvatic Triatoma sordida and Triatoma guasayana. Mem Inst Oswaldo Cruz 96: 385-389.

Romaña CA, Pizarro JCN, Rodas E, Guilbert E 1999. Palm trees as ecological indicators of risk areas for Chagas disease. Trans $R$ Soc Trop Med Hyg 93: 594-595.

Schofield CJ, Lehane MJ, McEwen P, Catalá SS, Gorla DE 1992. Dispersive flight by Triatoma infestans under natural climatic conditions in Argentina. Med Vet Entomol 6: 51-56.

SVS/MS - Secretaria de Vigilância em Saúde, Ministério da Saúde do Brasil 2005. Consenso brasileiro em doença de Chagas. Rev Soc Bras Med Trop 38 (Suppl. III): 1-29.

Valente SAS, Valente VC, Pinto AYN, Barbosa CMJ, dos Santos MP, Miranda CO, Cuervo P, Fernandes O 2009. Analysis of an acute Chagas disease outbreak in the Brazilian Amazon: human cases, triatomines, reservoir mammals and parasites. Trans $R$ Soc Trop Med Hyg 103: 291-297.

Valente VC, Valente SAS, Noireau F, Carrasco HJ, Miles MA 1998. Chagas disease in the Amazon basin: association of Panstrongylus geniculatus (Hemiptera: Reduviidae) with domestic pigs. J Med Entomol 35: 99-103.

Vázquez-Prokopec GM, Ceballos LA, Marcet PL, Cecere MC, Cardinal MV, Kitron U, Gürtler RE 2006. Seasonal variations in active dispersal of natural populations of Triatoma infestans in rural north-western Argentina. Med Vet Entomol 20: 273-279.

Wolff M, Castillo D 2000. Evidencias de domesticación y aspectos biológicos de Panstrongylus geniculatus (Latreille, 1811) (Hemiptera: Reduviidae). Acta Entomol Chil 24: 77-83.

Zeledón R, Ugalde JA, Paniagua LA 2001. Entomological and ecological aspects of six sylvatic species of triatomines (Hemiptera, Reduviidae) from the collection of the National Biodiversity Institute of Costa Rica, Central America. Mem Inst Oswaldo Cruz 96: 757-764. 